\title{
Combustion tube studies of dust flame acceleration
}

\author{
Yi-kang $\mathrm{Pu}^{1}$, Shan $\mathrm{Hu}^{1}$, Józef Jarosiński ${ }^{2}$ \\ ${ }^{1}$ Institute of Mechanics, Chinese Academy of Sciences, Beijing 100080, P. R. China \\ ${ }^{2}$ Institute of Aviation, Al. Krakowska 110/114, 02-256 Warsaw; Poland
}

Received / Accepted November 4, 1994

\begin{abstract}
A new pneumatic dispersion system for obtaining a good quality uniform dust suspension in a horizontal dust combustion tube was developed. The effect of three different dispersion techniques on self-sustained dust flame acceleration in such a combustion tube was examined. The importance of the dispersion quality in the test tube for maintaining a self-sustained dust flame acceleration was demonstrated. A combustion tube for studies of flame acceleration in fine aluminum dust-air mixture and its transition to detonation under industrial ignition conditions was constructed in the course of the present study. It consists mainly of an initiation section and a test section. The initiation section must be equipped in a well-developed dispersion system for creating a good dispersion condition in the test tube. The length of this section is 3 meters. The test tube requires only to distribute uniformly the dust over the bottom of the tube prior to the experiment. The aluminum dust spherical in shape with $6 \mu \mathrm{m}$ in diameter was used for tests. Experimental results demonstrated that the increase in flame velocity is roughly linear through the entire length of the test tube. The highest flame propagation velocity in fine aluminum dust-air mixture approaches some $1200 \mathrm{~m} / \mathrm{s}$ at a distance of $4.8 \mathrm{~m}$ from the ignition plate.
\end{abstract}

Key words: dust flame acceleration, transition to detonation, dust explosion

\section{Introduction}

The explosion characteristics, such as the maximum explosion overpressure, the maximum rate of pressure rise, the lower dust concentration limit for ignition, as a function of dust concentration, dust particle size (from 3 to $30 \mu \mathrm{m}$ ), dispersioninduced turbulence and concentration of oxygen in a mixture have been determined by two closed explosion vessels ( $\mathrm{Pu}$, $1990 ; \mathrm{Pu}, 1991)$. The experimental data in a form of explosion characteristics demonstrated that the fine aluminum dust is more violent than organic dust (grain, coal, etc.).

The detonation of flake aluminum powder with a surfaceto-mass ratio of 3 to $4 \mathrm{~m}^{2} / \mathrm{g}$ and atomized-aluminum powder with $0.34 \mathrm{~m}^{2} / \mathrm{g}$ and $5 \mu \mathrm{m}$ of particle diameter dispersed in air

Correspondence to: J. Jarosiński in a homogeneous manner were demonstrated to be readily achievable under the condition of having a strong shock wave initiation (Tulis, 1982). This study was conducted in a vertical tube $5.478 \mathrm{~m}$ long and with a $152 \mathrm{~mm}$ inside diameter, the measured detonation velocity and pressure are around $1.65 \mathrm{~km} / \mathrm{s}$, $5 \mathrm{MPa}$ for flake aluminum and $1.35 \mathrm{~km} / \mathrm{s}, 3 \mathrm{MPa}$ for atomizedaluminum powder.

With regard to dust explosion alleviation and dust detonation prevention, the investigation of the mechanism of fine aluminum dust flame acceleration and the transition process, which occur in a confined tube under industrial explosion conditions, becomes absolutely necessary.

In previous research, some attempts were made to study the acceleration of coal dust flame in horizontal with one open end tubes and channels (Slezak, 1983; Kauffman, 1984), and in full-scale experimental underground explosion test facilities (Richmond, 1975; Richmond, 1979; Pickles,1982). A few experiments of dust flame propagation were conducted in vertical tubes on both small and large scales (Essenhigh, 1958; Palmer, 1968; Palmer, 1971; Wolański, 1990). In order to achieve uniform dust particle suspension along the test tube, usually a uniform dust layer is spread along the bottom of the tube, then dispersed by upward directed air jets in a horizontal tube, and a free fall system consisting of a hopper and a screw device to feed the dust at the top of a long combustion tube in a vertical tube. It should be recognised that in both of the above mentioned techniques of dust dispersion, the creation of dust-air mixture in a test tube is followed by sedimentation, agglomeration and certain directed motion phenomena which affect the flame acceleration after the mixture is ignited.

It is also worth mentioning that in previous research, the dust flame propagation in a test tube, is usually ignited by a strong shock wave, which can be produced either by a detonation of high explosive (Tulis, 1982) or by a detonation of stoichiometric hydrogen and oxygen mixture (Kauffman, 1984). The method of initiating a dust flame propagation by detonation is used to ensure that the initial flame propagation velocity is fast enough. Under a weak ignition condition flame will meet no suspension of dust-air mixture in front of its propagation, the flame thus being decelerated until quenching occurs.

In the present study, the investigation into flame acceleration in transition to detonation in fine aluminum dust-air 


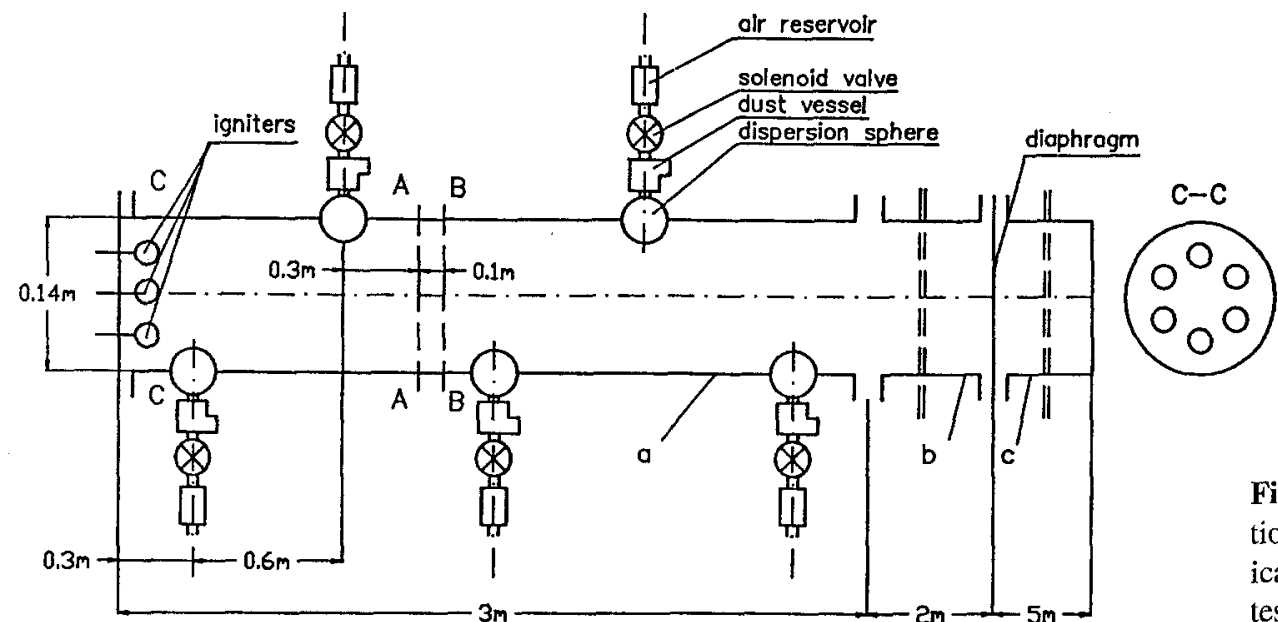

mixture is carried out under a weak ignition condition which is thought to exist in industrial accidents.

\section{Experimental details}

The horizontal combustion tube is $5 \mathrm{~m}$ long with $0.14 \mathrm{~m}$ inner diameter and $10 \mathrm{~mm}$ thickness of the wall. It consists of $3 \mathrm{~m}$ initiation section, and $2 \mathrm{~m}$ test section. The initiation section is equipped with a well-developed dispersion system, shown in Fig. 1.

The pneumatic dispersion system developed in the present study is essentially a hollow-spherical version of the circular perforated pipe which is used in the 20 liter sphere and the $1 \mathrm{~m}^{3}$ vessel by Barthnecht (Barthnecht,1980). It is composed of five individual hollow-spherical dispersion systems. Five dispersion spheres are equally spaced on the wall of the tube, in an order shown in Fig. 1. In each system the air flows from the pressurized cylinder ( 0.23 liter) and forces the dust in the dust chamber(0.01 liter) through a perforated hollow-sphere into the test tube. There are 82 dispersion orifices drilled on each hemi-spherical surface with the diameter of 1 to $1.8 \mathrm{~mm}$. The dispersion process is intrinsically transient during the $500 \mathrm{~ms}$, and the turbulence intensity decays during this process. The initial overpressure in the air reservoir is $0.6 \mathrm{MPa}$.

The turbulence measurement accomplished by hot probes and anemometers is carried out in the air. The voltage signals coming from anemometers for the instantaneous flow velocity of each experiment are recorded and stored in a personal computer memory (floppy disks), then processed on the basis of the ensemble average method $(\mathrm{Pu}, 1989)$ by a computer. In the measurements, the hot wire probe is fixed at the center of the cross-section A (see Fig. 1).

Initial distribution of dispersed dust concentration along the axis of the $3 \mathrm{~m}$ initiation section is roughly examined by observation of the dust layer thickness at the bottom of the tube after dispersion. The qualitative evaluation of the duration of dispersed dust particle suspension is monitored by transmission measurements, through the $0.14 \mathrm{~m}$ inside the diameter of the test tube at the cross-section A and B, shown in Fig. 1.

To achieve planar flame propagation, six igniters are mounted uniformly on the closed end of the initiation section.
Each igniter contains 1 gram of black powder inside a paper capsule and is ignited by a small fuse head. The total ignition energy produced by six igniters is about $2770 \mathrm{~J}(60 \mathrm{~J} / \mathrm{liter})$, the rate of pressure rise in the closed tube being about $2 \mathrm{MPa} / \mathrm{s}$.

Four piezoelectric transducers having a sensitivity of $0.001-0.002 \mathrm{MPa} / \mathrm{mV}$ are used to indicate the pressure history in the combustion process. The transducers are located on the wall along the tube at a distance of $1 \mathrm{~m}, 2 \mathrm{~m}, 4 \mathrm{~m}, 4.8 \mathrm{~m}$ from the plate $\mathrm{C}$, and the signals are recorded on oscilloscopes.

The flame is detected by eight photodiodes which are located on the wall in orifices spaced every $10 \mathrm{~cm}$ along the axis of the tube. The signals are recorded by a 4-channel recorder with a sampling rate of $40 \mu \mathrm{s}$, if the flame propagation velocity is below $300 \mathrm{~m} / \mathrm{s}$ and by a 4-channel recorder with a sampling rate of $0.1 \mu \mathrm{s}$, if the flame propagation velocity is over $300 \mathrm{~m} / \mathrm{s}$.

An atomized-aluminum dust-air mixture with a dust concentration of $500 \mathrm{~g} / \mathrm{m} 3$ is used for the tests. The scanning electron micrograph indicates the aluminum particles spherical in shape. The mean particle diameter is $6 \mu \mathrm{m}$. Cornstarch dust with oxygen ( $96 \%$ of $\mathrm{O}_{2}+4 \%$ of $\mathrm{N}_{2}$ ) is also used in some of the tests for the investigation of then well-developed dispersion system, because cornstarch dust is much easier and cheaper to be purchased than aluminum dust. From an explosion point of view, cornstarch dust in the air is a much less sensitive reacting substance than atomized-aluminum dust. Adding $96 \%$ oxygen to cornstarch dust, the resulted mixture achieves almost the same level of explosivity as aluminum dust in the air.

\section{Experimental results and discussion}

\subsection{The examination of quality of the developed dust dispersion system}

Developed dust dispersion system installed in the initiation section (System I) creates a homogeneous dust particle suspension in the tube. This was proved by observing that the thickness of the dust layer along the tube, is practically the same for some time after dispersion.

Figure 2 presents the measurement results of dispersioninduced turbulence parameters, as a function of time, at the 

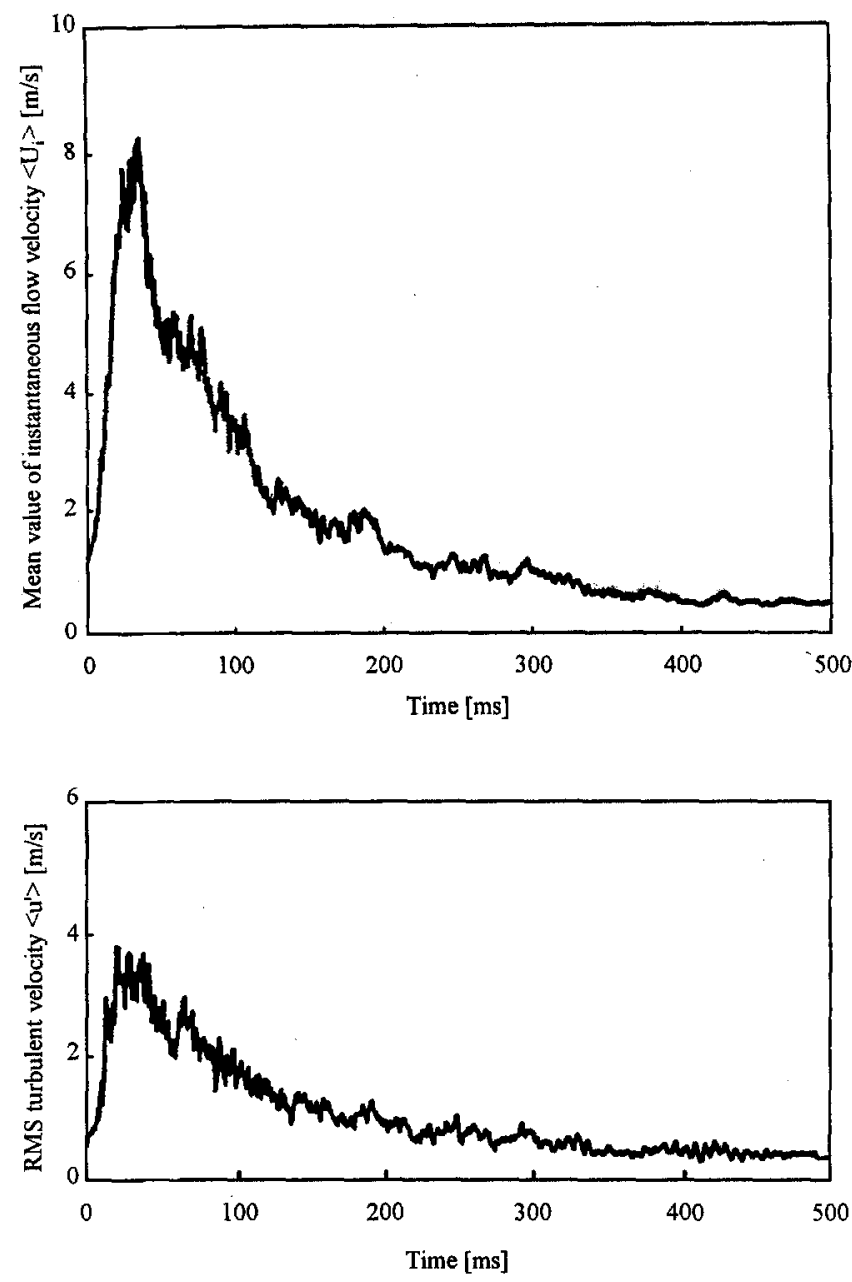

Fig. 2. The dispersion-induced turbulent parameters measured as a function of time at the center of the cross section A. a the ensemble average of instantaneous flows velocity; $\mathbf{b}$ the ensemble average of RMS velocity

center of the cross-section located in the middle position between two adjacent dispersion sphere. Experimental results showed that the dispersion process in the test tube is intrinsically transient for a period of $200 \mathrm{~ms}$. The peak values of mean flow and RMS turbulence velocity in the transient dispersion process both occur about $20 \mathrm{~ms}$ after activation of the solenoid valve and are $8 \mathrm{~m} / \mathrm{s}$ and $3 \mathrm{~m} / \mathrm{s}$, respectively. Starting out from $20 \mathrm{~ms}$ to $100 \mathrm{~ms}$ after activation of the solenoid valve, both velocities decrease rapidly to $2.5 \mathrm{~m} / \mathrm{s}$ and $1.2 \mathrm{~m} / \mathrm{s}$, respectively, then from $100 \mathrm{~ms}$ to $200 \mathrm{~ms}$ decrease slowly to almost zero. In the present study the ignition delay time is about $20 \mathrm{~ms}$. This means that during flame propagation from $20 \mathrm{~ms}$ to $200 \mathrm{~ms}$ after the solenoid valve is activated, the combustion process goes on with the decaying transient turbulence. It is suggested $(\mathrm{Pu}, 1991)$ that the dispersion-induced turbulence may only play an important role for the dispersion, formation and suspension of dust-air mixture rather than acting on combustion, which means that the influence of turbulence on the combustion process is exerted mainly through the initial conditions of dust-air mixture formation.

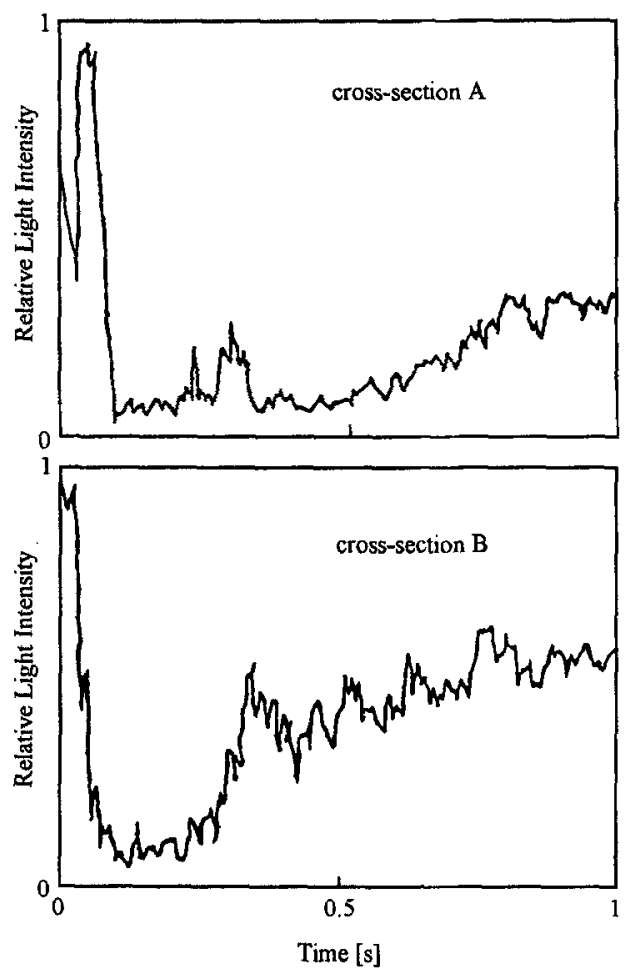

Fig. 3. The light transmission versus the time after the atomizedaluminum dust particles were dispersed into the initiation section. a At the cross-section A; $\mathbf{b}$ at the cross-section $\mathrm{B}$

Figure 3 presents the measurement results of light transmission, as a function of time, in two cross-sections $\mathrm{A}$ and B. The experimental results demonstrate that in both above sections the suspension of dispersed dust particles roughly start in $20-30 \mathrm{~ms}$ after the activation of the solenoid valve, then kept until $500 \mathrm{~ms}$. Combining the experimental results obtained from Figs. 2 and 3, it can be recognized that the dispersion systems developed in the present study has a duration between $20 \mathrm{~ms}$ to $500 \mathrm{~ms}$.

\subsection{Two other dispersion systems employed for comparison}

The second system (System II) is similar to those, in which the dust is placed on the bottom of the tube prior to the experiment and dispersed by introducing gas flow through a small dispersion tube having orifices in one row located opposite to the bottom of the test tube. In the third system (System III), which is used in many experiments, the dust is placed at the bottom of the test tube, without introducing any gas flow.

\subsection{The effect of the dispersion technique on self-sustained dust flame acceleration}

It is instructive to examine the flame propagation process under various conditions of dispersion by employing a test tube with two closed ends. It was decided to use closed ends to investigate the effectivness of the three different dispersion systems in preliminary experiments. Although the phenomena of flame propagation under a constant volume condition 
is rather complicated, the advantage of having a highly accurate pressure history, flame arrival measurements and ensuring the amount of dust participating in the combustion makes the constant volume combustion useful. While the measured maximum overpressure is linked directly with the energy release, the maximum rate of pressure rise characterizes globally the combustion rate in the closed vessel. As regards constant volume combustion, the known amount of dust participating in the combustion process gives a reliable basis to the examination of different dispersion techniques.

Figure 4(a) presents three curves of flame propagation velocity in a mixture of cornstarch dust with $96 \%$ of oxygen, as a function of the distance along the axis of the test tube from the ignition plate. Those curves are obtained under different dispersion conditions by employing the dispersion techniques of System I, II and III. Experimental results in Fig. 4(a) demonstrate the importance of the dispersion conditions for the flame propagation process in the closed tube. In the System I, the flame propagation velocity is about $200 \mathrm{~m} / \mathrm{s}$ at a distance of $1 \mathrm{~m}$ from the ignition plate and increases linearly to about $550 \mathrm{~m} / \mathrm{s}$ at a distance of $2.7 \mathrm{~m}$ from the ignition plate. In the System II, the flame propagation velocity is about $100 \mathrm{~m} / \mathrm{s}$ at a distance of $1 \mathrm{~m}$ from the ignition plate and increases almost linearly to $290 \mathrm{~m} / \mathrm{s}$ at a distance of $2.1 \mathrm{~m}$, then decreases rapidly to $70 \mathrm{~m} / \mathrm{s}$ at a distance of $2.7 \mathrm{~m}$. In the System III, the propagation of the flame is very weak without acceleration, and the corresponding propagation velocity is about $5 \mathrm{~m} / \mathrm{s}$. There is some similarity in the type of flame acceleration between Systems I and II, the flame accelerating linearly in both cases and taking the same rate of acceleration along the tube, that is $200 \mathrm{~m} / \mathrm{s}$ per $1 \mathrm{~m}$ of tube length. It is obvious that from the point of view of the flame propagation velocity the System I is the most effective of the systems used. The flame accelerates along the entire tube length in the System I. If the System II is used, it decelerates at a distance from $2 \mathrm{~m}$ to the end. This shows that the developed dispersion system produces much better dispersion conditions in the test tube for a self-sustained acceleration of dust flame than other dust dispersion techniques.

Figures 4(b) and 4(c) present some examples of pressure history measured during the combustion process in the closed tube filled with a mixture of cornstarch dust with $96 \%$ of oxygen under the dispersion conditions for the System I and II. The two typical curves, shown in Fig. 4(b) represent the pressure measured on the center of the end plate of the closed tube. The other two typical curves, shown in Fig. 4(c), represent the pressure measured on the tube wall at a distance of $2 \mathrm{~m}$ from the ignition plate. The pressure perturbations are observed from Fig. 4(b) and 4(c). The wave propagation velocity between pressure peaks is about $1000 \mathrm{~m} / \mathrm{s}$ for both Systems, I and II. This shows that the flow velocity in front of the flame, which is produced by flame acceleration, is very high and that shock waves are reflected many times by the closed ends of the test tube. Experimental results demonstrate also that the maximum value of explosion overpressure and the rate of pressure rise, which are measured on the closed end of the tube at a distance of $3 \mathrm{~m}$ from the ignition plate, occurs at the first peak in the perturbed pressure curve for the System I, and at the second peak for the System II. The measured data at the first peak are used for characterizing the explosion process in the closed tube. The maximum value of explosion overpressure and the rate of pressure rise are $4.2 \mathrm{MPa}$ and $3000 \mathrm{MPa} / \mathrm{s}$ for the System I, and $1.4 \mathrm{MPa}$ and $300 \mathrm{MPa} / \mathrm{s}$ for the System II. In the closed tube the values of maximum explosion overpressure and the maximum rate of pressure rise obtained under the dispersion conditions of the System I are 3 and 10 times as high as those obtained under the dispersion conditions of the System II. The values of the maximum rate of pressure rise obtained from the pressure measurements at the tube wall somehow relate to the flame acceleration process. The measured data are $240 \mathrm{MPa} / \mathrm{s}$ for the System I and $150 \mathrm{MPa} / \mathrm{s}$ for the System II, respectively. It shows indirectly that the flame propagates much faster under the dispersion conditions of the System I than under the conditions of the System II. All the experimental results above show the important effect of the dispersion conditions on the explosion characteristics in a constant volume combustion process.

\subsection{The determination of the necessary length of the initiation section}

The importance of the dispersion condition for flame acceleration has been demonstrated in the closed tube study. Since the effective flame acceleration process in the initiation section near the end has speeded up, the flow velocity in front of the flame becomes very high until a shock wave is generated. In this case, the dust in the test tube can be picked up from the bottom of the tube and kept in suspension by the shock wave, therefore, the remaining part of the test tube would not need to be equipped with any dust dispersion system. A uniform dust layer is spread at the bottom of the test tube prior to each experiment. The remaining question is how long the length of the initiation section should be. There is no doubt that if that length is greater more dispersion heads are needed and the acceleration of the dust flame is higher. The determination of the length necessary for the initiation section is accomplished by the following three sets of experiments. All the experiments are carried out in closed test tube, of $3 \mathrm{~m}$ long with different numbers of dispersion heads in given sets of experiments: five, three and one. The corresponding lengths of initiation section are $3 \mathrm{~m}, 2 \mathrm{~m}, 1 \mathrm{~m}$, respectively. In the remaining part of the tube, the dust is located at the bottom of the tube prior to the experiment.

Figure 5 presents the flame propagation velocity along the axis of the test tube in the three sets of experiments described above. Cornstarch dust with $96 \%$ of oxygen is used for testing. By confronting the flame acceleration in the above three sets of experiments, the $3 \mathrm{~m}$ long tube can be considered as a limit length necessary for the initiation section. This length may vary for different kinds of dust, various concentrations, size of particle, content of $\mathrm{O}_{2}$ or $\mathrm{N}_{2}$,etc. Detailed study of all these parameters influence will be undertaken in the future. 

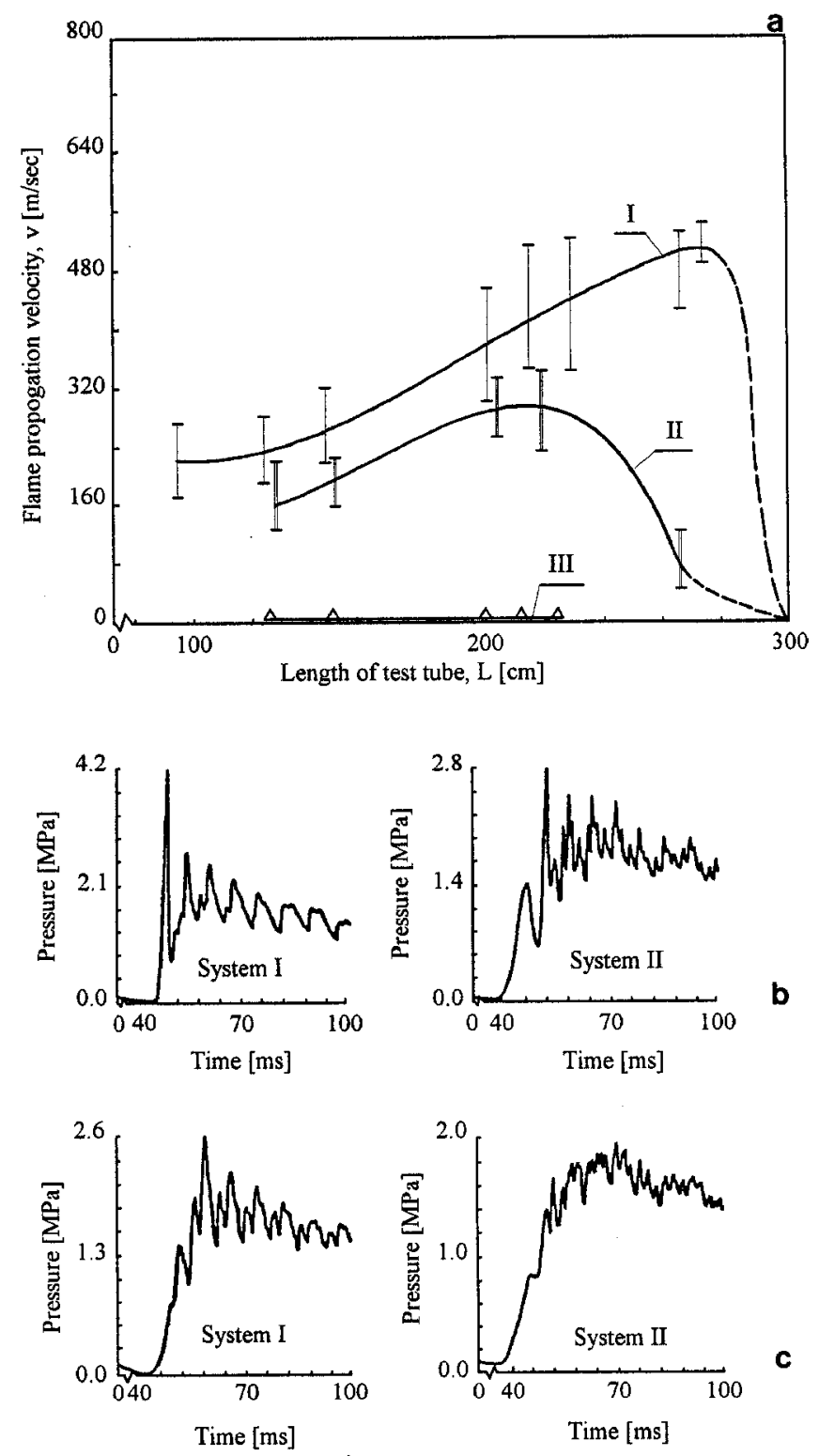

Fig. 4. A comparison of the effect of three different dispersion techniques on the flame propagation process in a $3 \mathrm{~m}$ closed tube in cornstarch with technical oxygen ( $96 \%$ of $\mathrm{O}_{2}+4 \%$ of $\mathrm{N}_{2}$ ) having dust concentration $500 \mathrm{~g} / \mathrm{m}^{3}$. a Flame propagation velocity as a function of tube length; $\mathbf{b}$ pressure history measured on the end plate of closed tube; $\mathbf{c}$ pressure history measured on the tube wall at a $2 \mathrm{~m}$ distance from the ignition plate $\mathrm{C}$

\subsection{Flame acceleration in fine aluminum dust-air mixture}

An atomized-aluminum dust flame propagation was carried out in the above constructed combustion tube explained above. Figure 6(a) shows the propagation velocity along the axis of the tube in an atomized-aluminum dust-air mixture. Those results show that the aluminum dust flame keeps accelerating through the entire length of the test tube, almost linearly, at a rate of speed along the tube about $270 \mathrm{~m} / \mathrm{s}$ per $1 \mathrm{~m}$ of tube length. The flame propagation velocity approaches almost $1200 \mathrm{~m} / \mathrm{s}$ at the distance of $4.8 \mathrm{~m}$ from the ignition plate. Figure $6(\mathrm{~b})$ shows the pressure history, measured on the tube wall, at a

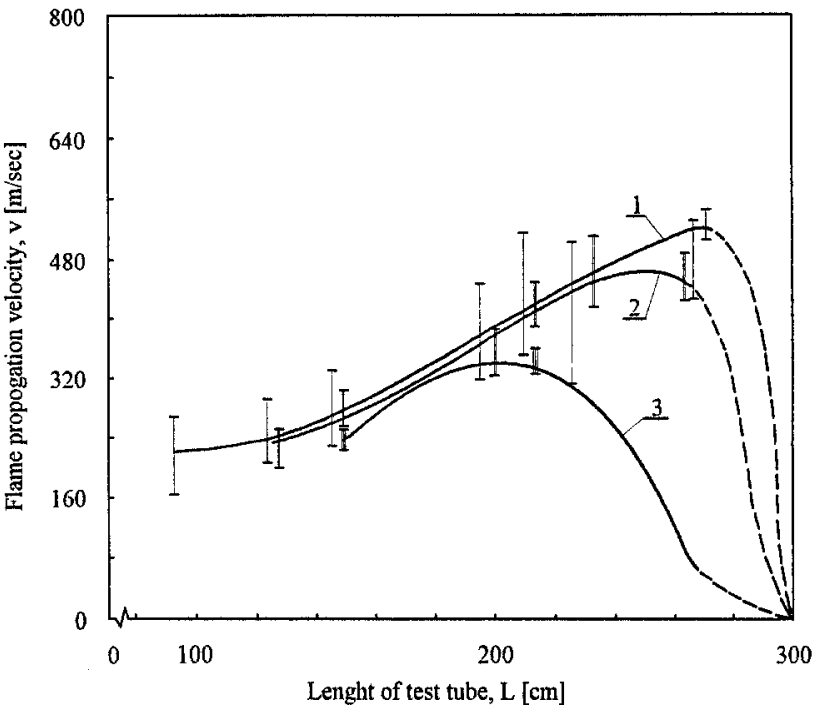

Fig. 5. The influence of the length of the initiation section on the flame propagation in a $3 \mathrm{~m}$ closed tube in the cornstarch with technical oxygen ( $96 \%$ of $\mathrm{O}_{2}+4 \%$ of $\mathrm{N}_{2}$ ) having dust concentration $500 \mathrm{~g} / \mathrm{m}^{3}$

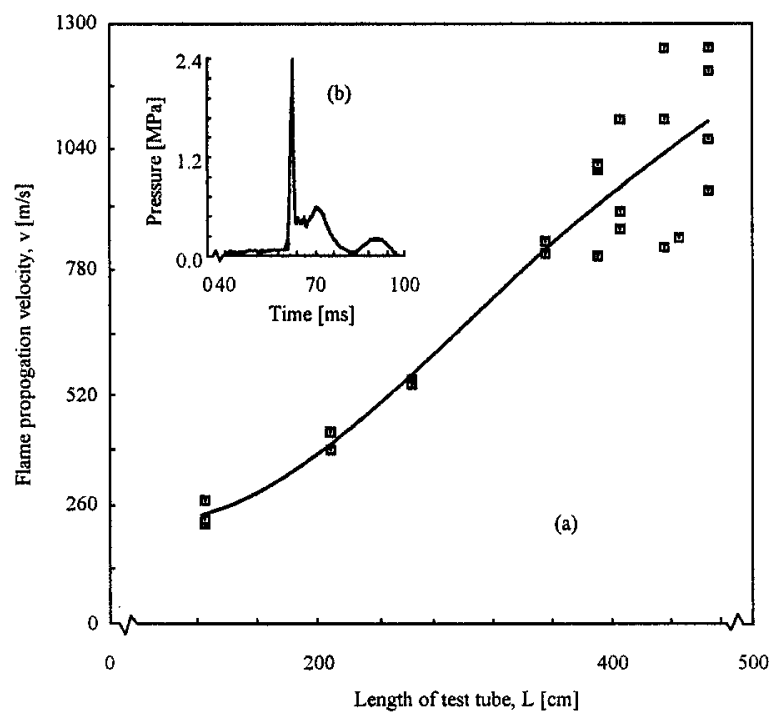

Fig. 6. Flame acceleration in fine aluminum dust-air mixture in the $5 \mathrm{~m}$ long horizontal combustion tube. a Flame propagation velocity as a function of tube length; $b$ pressure history measured on the tube wall at a distance of $4.8 \mathrm{~m}$ from the ignition plate $\mathrm{C}$

distance of $4.8 \mathrm{~m}$ from the ignition plate. These data show that the maximum rate of pressure rise approaches $500 \mathrm{MPa} / \mathrm{s}$ and the maximum pressure on the wall of the tube, at that crosssection, is $2.4 \mathrm{MPa}$.

\section{Summary}

The effect of the dispersion technique on the self-sustained flame acceleration in a mixture of fine aluminum dust with air in a horizontal combustion tube has been investigated. A combustion tube has been constructed to study acceleration of such flame and its transition to detonation under conditions of weak ignition similar to those which would happen in the industry 
producing aluminum powder. A local accidental blast producing good suspension of dust with following weak ignition can happen under real powder industry conditions. The facility developed to meet similar conditions consists of an initiation section and a test section. The initiation section is equipped by a well-developed dispersion system. In the test section the dust is placed at the bottom of the tube. The length of both sections used in the present study is $3 \mathrm{~m}$ for the initiation section and $2 \mathrm{~m}$ for the test section, respectively. A constant flame acceleration, of about $270 \mathrm{~m} / \mathrm{s}$ per $1 \mathrm{~m}$ of tube length, is obtained almost for the entire tube length. The highest flame propagation velocity at the end of the last section is about $1200 \mathrm{~m} / \mathrm{s}$. The data collected in the above combustion tube should help to understand the mechanisms of flame acceleration in fine aluminum dust-air mixtures and in the prevention and alleviation of accidental explosions in industrial plants which involve aluminum powder presence and its production.

\section{References}

Bartknecht, W. (1980) Explosions-Course, Prevention, and Protection, (Translated by Burg, H. and Almond, T.) Springer, New York

Essenhigh, R.H., Woodhead D.W. (1958) Speed of Flame in Slowly Moving Clouds of Cork Dust. Combustion and Flame 2, 365

Kauffman, C.W., Srinath, S.R., Tezok, F.I., Nicholls, J.A., Sichel, M. (1984) Turbulent and Accelerating Dust Flames. Twenty Symposium (International) on Combustion, The Combustion Institute, p. 1701

Palmer, K.N., Tonkin, P.S (1968) International Chemistry Industry Symposium Series, INSTN Chem. Engrs. London No. 25, p. 102
Palmer, K.N., Tonkin, P.S. (1971) Coal Dust Explosions in a LargeScale Vertical Tube Apparatus. Combustion and Flame 17, 159

Pickles, J.H. (1982) A Model for Coal Dust Duct Explosions. Combustion and Flame 44, 153

Pu, Y.K., Jarosinski, J., Johnson, V.G., Kauffman, C.W. (1991) The Investigation of the Feature of Dispersion Induced Turbulence and Its Effects on Dust Explosion in the 20 Liter Spherical Vessel. Twenty-third Symposium (International) on Combustion, The Combustion Institute, pp. 843

Pu, Y.K., Yuan, S.X., Ding, D.Y., Wang B.L., Tang, M.J. (1990) The Investigation of Explosion Characteristics in Fine Aluminum Dust-Air Mixtures. Proceedings of the Fourth International Colloquium on Dust Explosion, Porabka-Kozubnik, Poland, pp. 159

Pu, Y.K., Li, Y.C., Kauffman, C.W., Bernal, L.P. (1989) Determination of Turbulence Parameters in Closed Explosion Vessels. AIAA Progress in Astronautics and Aeronautics, vol. 132, p. 107

Richmond, T.K., Liebman, L. (1975) A Physical Description of Coal Mine Explosions. Fifteenth Symposium (International) on Combustion, The Combustion Institute, p. 115

Richmond, T.K., Liebman, L. (1979) A Physical Description of Coal Mine Explosions. Part II. Seventeenth Symposium (International) on Combustion, The Combustion Institute, p. 1257

Slezak, S.E., Fitch, D.J., Krier, H., Buckius, R.O. (1983) Coal Dust Flame Propagation in a Laboratory Flammability Tube. Combustion and Flame 54, p. 103

Tulis, A.J., Selman, J.R. (1982) Detonation Tube Studies of Aluminum Particles Dispersed in Air. Nineteenth Symposium (International) on Combustion, The Combustion Institute, p. 655

Wolański, P., Sacha, W., Zalesinski, M. (1990) Effect of Dust Concentration on Detonation Parameters in Grain Dust-Air Mixtures. Proceedings of the Fourth International Colloquium on Dust Explosion, Porąbka-Kazubnik, Poland, pp. 335-370 